\title{
DEDICATION OF THE WANGENSTEEN HISTORICAL LIBRARY AT THE UNIVERSITY OF MINNESOTA
}

On Tuesday 21 November 1972 the Owen H. Wangensteen Historical Library of Biology and Medicine was dedicated at the University of Minnesota. The dedication ceremony began at 3.30 p.m. with brief speeches by Dr. Leonard G. Wilson, professor of the history of medicine, Mr. Glenn Brudvig, Biomedical Librarian, Mr. John Yngve of the Board of Regents of the University, and Dr. Lyle French, vice-president for Health Sciences Affairs. President Malcolm Moos presented Dr. Wangensteen with a citation, and Dr. Wangensteen himself spoke. Afterwards there was a reception in the library.

Dr. Owen H. Wangensteen has been the driving force behind the development of the historical collections in biology and medicine at Minnesota into an outstanding library of more than 20,000 volumes. In 1964, largely through his efforts, the fifth floor was added to Diehl Hall to provide space for the historical collections of the Biomedical Library. In addition to the book stacks there is a reading room, an exhibit and reception area, a lecture room, work room, offices for the library staff and the Department of the History of Medicine and studies and carrels.

The library collections are particularly rich in American medicine, anatomy and surgery, ophthalmology, and cardiology. There is a fine collection of sixteenthcentury herbals and of writings by and about Linnaeus, as well as a broad general representation of early works in medicine and the biological sciences.

\section{XIVth INTERNATIONAL CONGRESS OF THE HISTORY OF SCIENCE Tokyo-Kyoto (Japan) 17-27 August 1974}

The XIVth International Congress of the History of Science will be held in Japan in August 1974. The provisional time-table is as follows:

17-24 August 1974 Scientific sessions and business meetings in Tokyo

26-27 August 1974 Symposia in Kyoto

Further details will be announced shortly.

\section{QUERIES}

Dr. E. H. Hare (The Bethlem Royal Hospital, Monks Orchard Road, Beckenham, Kent BR 3 3BX) is trying to trace two manuscript medical case books of Peter Mere Latham (1785-1875). Dr. Latham was physician to Michael Faraday at the time of the onset of Faraday's illness (1839), and the two case books cover the period from May 1839 to December 1844.

Dr. Glynne R. Jones (University Hospital of Wales, Heath Park, Cardiff CF4 4XW) is seeking a portrait of Dr. David Daniel Davis, M.D., F.R.C.P. (1777-1841), a Welshman who was physician-accoucheur at the birth of Queen Victoria and who subsequently was the first to hold the chair in Midwifery at University College London. The portrait is said to have been painted by John Jackson, R.A., in 1825, and was in the possession of the Davis family in 1878 , but its present whereabouts are unknown. 